\title{
Acute respiratory failure due to tracheobronchial involvement in Crohn's disease
}

\author{
C. Lamblin*, M-C. Copin*, C. Billaut*, R. Marti+, V. Tacq ${ }^{++}$, O. Riviere ${ }^{\dagger}$, B. Wallaert*
}

\begin{abstract}
Acute respiratory failure due to tracheobronchial involvement in Crohn's disease. $C$. Lamblin, M-C. Copin, C. Billaut, R. Marti, V. Tacq, O. Riviere, B. Wallaert. (CERS Journals Ltd 1996.

ABSTRACT: We present a case of tracheobronchial involvement in Crohn's disease, associated with respiratory failure leading to mechanical ventilation.

Bronchoscopy revealed small, diffuse, whitish granulations and erythematous mucosa. Histopathology disclosed ulcerative bronchitis and noncaseating tuberculoid granuloma. The patient improved under a 6 week oral corticosteroid treatment followed by inhaled corticotherapy, without relapse of pulmonary symptoms. Eur Respir J., 1996, 9, 2176-2178.
\end{abstract}

\author{
* Service de Pneumologie et Immuno-Aller- \\ gologie, **Service d'Anatomo-Pathologie \\ C, Hôpital A. Calmette, Lille, France. \\ +Maladies de l'appareil digestif et de la \\ nutrition, Calais, France. ${ }^{++}$Cabinet de \\ Pneumologie, Calais, France. †Cabinet \\ d'anatomie et de cytologie pathologiques, \\ St Omer, France. \\ Correspondence: B. Wallaert, Service de \\ Pneumologie et Immuno-allergologie, Hopital \\ A. Calmette, Boulevard du Professeur \\ Leclercq, 59037 Lille Cedex, \\ France \\ Keywords: Acute respiratory failure, Crohn's \\ disease, lung \\ Received: November 211995 \\ Accepted after revision April 301996
}

Crohn's disease (CD) is an inflammatory bowel disease which may affect virtually all organs, including the lung. However, few cases of lung involvement in $\mathrm{CD}$ have previously been reported [1], such as granulomatous interstitial pneumonitis [2-4], fistula [5], bronchiectasis [6] and sulphasalazine-induced pneumonitis [7]. Among these manifestations, bronchial and/or tracheal localizations are very rare $[8,9]$. We report the case of a patient with diffuse tracheal and bronchial localizations of $\mathrm{CD}$ leading to respiratory failure.

\section{Case report}

A 37 year old man was admitted to the intensive care unit in December 1993, for acute dyspnoea, requiring immediate intubation and mechanical ventilation. He was a moderate smoker (10 pack-yrs) and had no previous history of respiratory disease. In February 1992, he exhibited episodic bloody stools; proctological examination revealed haemorrhoids. Complete colonoscopy was considered normal. Systemic caecal biopsies revealed a mild nonspecific inflammatory infiltrate throughout the lamina propria, consisting of lymphocytes and plasmocytes.

On admission, respiratory failure was associated with recent loss of weight (6 kg in 1 month), fever, increasing weakness, abdominal pain and diarrhoea for 15 days. On examination, the patient was in respiratory distress and had productive cough with diffuse wheezing and mild abdominal tenderness. The temperature was $38^{\circ} \mathrm{C}$. Laboratory data at admission showed the following abnormalities: white blood cell counts $21.4 \times 10^{9}$ cells $\cdot \mathrm{L}^{-1}$, $89 \%$ segmented cells, erythrocyte sedimentation rate
(ESR) $64 \mathrm{~mm} \cdot \mathrm{h}^{-1}, \mathrm{C}$-reactive protein $(\mathrm{CRP}) 167 \mathrm{mg} \cdot \mathrm{L}^{-1}$ (normal $<3 \mathrm{mg} \cdot \mathrm{L}^{-1}$ ), potassium $2.3 \mathrm{mmol} \cdot \mathrm{L}^{-1}$, creatinine 18 $\mathrm{mg} \cdot \mathrm{mL}^{-1}$, blood urea $0.52 \mathrm{~g} \cdot \mathrm{L}^{-1}$ and albuminaemia, albu$\min 26.8 \mathrm{~g} \cdot \mathrm{L}^{-1}$ (normal range $30-45 \mathrm{~g} \cdot \mathrm{L}^{-1}$ ). Arterial blood gas values before intubation on room air showed severe hypo-ventilation: arterial oxygen tension $\left(\mathrm{Pa}_{\mathrm{a}} \mathrm{O}_{2}\right) 4.4 \mathrm{kPa}$ $(33 \mathrm{mmHg})$, arterial carbon dioxide tension $\left(\mathrm{Pa}_{\mathrm{a}} \mathrm{CO}_{2}\right) 9.5$ $\mathrm{kPa}(71 \mathrm{mmHg})$, arterial oxygen saturation $\left(\mathrm{Sa}_{\mathrm{a}} \mathrm{O}_{2}\right) 54 \%$, $\mathrm{pH}$ 7.30. Repeated microbiological examinations of sputum, stool cultures and parasitic research in the stools remained negative. Chest radiographic image was normal. Treatment consisted of mechanical ventilation, intravenous $\beta_{2}$-mimetics, parental amoxycillin and clavulanic acid $\left(3 \mathrm{~g} \cdot \mathrm{day}^{-1}\right)$ and parental methylprednisolone (80 $\mathrm{mg} \cdot$ day $^{-1}$ ), leading to rapid clinical improvement. On Day 3 , extubation was possible; arterial blood gas values with inspiratory oxygen fraction $\left(F \mathrm{I}, \mathrm{O}_{2}\right) 30 \%$ were: $\mathrm{Pa}_{\mathrm{a}} \mathrm{O}_{2} 18.1$ $\mathrm{kPa}(136 \mathrm{mmHg}), 6.0 \mathrm{kPa}(45 \mathrm{mmHg}), \mathrm{pH} 7.43$.

On Day 4, the patient continued to exhibit dry cough and diarrhoea. Colonoscopy was performed and revealed small petechiae confined to the sigmoid colon, without other abnormality. Rectal biopsies showed that the mucosa was the setting of microscopic colitis with mild cryptic lesions, without granulomas. These histological findings were consistent with Crohn's disease. Upper gastro-intestinal endoscopy was macroscopically normal; both gastric and duodenal biopsies were normal, showing no granulomas. Barium small bowel radiographs were also normal, showing no sign of inflammatory bowel disease.

On Day 11, the patient became free of respiratory and abdominal symptoms and was discharged without further treatment. 


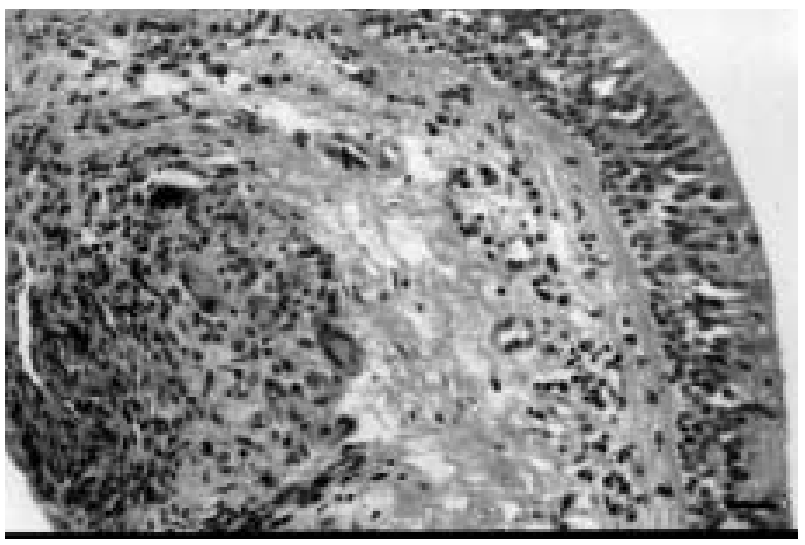

Fig. 1. - Bronchial biopsy at Day 20. Exsudative inflammatory reaction consisting of a majority of neutrophils infiltrating the bronchial mucosa. The bronchial epithelium undergoes squamous metaplasia without dysplasia. (Haematoxylin and eosin stain; magnification $\times 100$; internal scale bar $=50 \mu \mathrm{m})$.



Fig. 2. - Bronchial biopsy at Day 28. Epithelial granulomas without necrosis are present within the bronchial wall. There is an admixture of lymphocytes with epithelioid cells and some multinucleate giant cells. (Haematoxylin and eosin stain; magnification $\times 100$; internal scale bar=50 $\mu \mathrm{m})$.

On Day 20, he was readmitted with a dry, continuous and exhausting cough. Upper airway and chest examinations were normal and there were no abdominal symptoms. Laboratory data showed elevated ESR $\left(115 \mathrm{~mm} \cdot \mathrm{h}^{-1}\right)$ and CRP $\left(200 \mathrm{mg} \cdot \mathrm{L}^{-1}\right)$. Microbiological examinations of sputum were negative. Chest radiography and high resolution computerized tomography (HRCT) were normal. Fibreoptic bronchoscopy was performed and disclosed erythematous mucosa of the trachea and main stem bronchus, with diffuse whitish granulations. Biopsies showed ulcerative bronchitis associated with squamous cell metaplasia; the lamina propria was the setting of small abscesses, just beneath the ulceration (fig. 1).
Antibiotherapy was instituted on Day 20 (amoxycillin, $\left.3 \mathrm{~g} \cdot \mathrm{day}^{-1}\right)$, associated with ciprofloxacin, $\left.1.5 \mathrm{~g} \cdot \mathrm{day}^{-1}\right)$. This treatment led to clinical improvement and normalization of inflammatory parameters. On Day 28, bronchoscopy showed moderate erythematous bronchial mucosa without granulations. Bronchial biopsies revealed nonnecrotizing granuloma with epithelioid and giant cells (fig. 2). Staining for microorganisms, including acid-fast bacilli was negative, as was the culture for mycobacteria. Bronchoalveolar lavage was normal: $109 \times 10^{3}$ cells $\cdot \mathrm{mL}^{-1}$ in $88 \mathrm{~mL}$, with $92 \%$ macrophages, $7 \%$ lymphocytes and $1 \%$ neutrophils. Serum angiotensin converting enzyme (SACE) was normal. According to clinical and endoscopic improvement, the patient was discharged, without treatment.

One month later (February 1994), dry cough recurred. There were still no abdominal symptoms and chest radiographic image was normal. Bronchoscopy revealed a pronounced inflammatory and ulcerative aspect both of the trachea and main bronchi. Histological findings showed normal bronchial epithelium, thickened basal membrane and a dence inflammatory infiltrate in the lamina propria, consisting of lymphocytes, plasma cells and eosinophils. Pulmonary function tests (PFT) showed an obstructive ventilatory syndrome (table 1). According to previous histological findings, respiratory symptoms were considered as the expression of possible bronchial localization of CD. Oral corticotherapy was prescribed, starting at $1.5 \mathrm{mg} \cdot \mathrm{kg}^{-1}$ daily for 10 days, and was then progressively reduced for a total duration of 6 weeks, followed by inhaled steroids (budesonide 1,600 $\mu \mathrm{g} \cdot \mathrm{day}^{-1}$ ). At the end of the treatment, the patient was asymptomatic, bronchoscopy was normal and PFT revealed a mild but persistent obstructive syndrome (table 1). Biopsies showed nonspecific fibrous changes, without granulomas. Inhaled corticotherapy was progressively reduced to $800 \mu \mathrm{g} \cdot \mathrm{day}^{-1}$. No clinical pulmonary relapse occurred and PFT showed mild airways obstruction in November 1994 (table 1).

In April 1995, the patient presented with bloody diarrhoea, loss of weight, weakness and abdominal pain. There were no respiratory symptoms. Colonoscopy disclosed small ulcerations of the rectum and sigmoid colon and hyperhaemic mucosa on the whole colon. Multiple biopsies were performed in the caecum, right colon, sigmoid colon and rectum. They showed patchy lesions, with zones of normal mucosa, and interstitial focal infiltration consisting of macrophages and plasma cells associated with cryptic abscesses. These histological abnormalities were sometimes encountered beside normal mucosa on the same biopsy. Mucus secretion was not increased. The clinical evolution and bowel histological findings confirmed CD. Spirometric measurement were comparable with those obtained in November 1994 (table 1).

Table 1. - Sequential evaluation of pulmonary function tests

\begin{tabular}{|c|c|c|c|c|c|c|c|c|c|c|c|}
\hline \multirow[b]{2}{*}{ Date } & \multicolumn{2}{|r|}{ FVC } & \multicolumn{2}{|c|}{ FEV1 } & \multirow{2}{*}{$\begin{array}{c}\mathrm{FEV}_{1} / \mathrm{FVC} \\
\%\end{array}$} & \multicolumn{2}{|c|}{ FEF25 } & \multicolumn{2}{|c|}{ FEF50 } & \multicolumn{2}{|c|}{ FEF75 } \\
\hline & $\mathrm{L}$ & $\%$ pred & $\mathrm{L}$ & $\%$ pred & & $\mathrm{L} \cdot \mathrm{s}^{-1}$ & $\%$ pred & $L \cdot \mathrm{s}^{-1}$ & $\%$ pred & $\mathrm{L} \cdot \mathrm{s}^{-1}$ & $\%$ pred \\
\hline 23.02 .94 & 5.2 & 103 & 3.3 & 79 & 63 & 1.4 & 58 & 2.4 & 45 & 3.5 & 42 \\
\hline 18.04 .94 & 5.8 & 114 & 3.8 & 90 & 67 & 1.3 & 56 & 3.1 & 59 & 4.7 & 57 \\
\hline 09.11 .94 & 5.7 & 113 & 4.0 & 97 & 70 & 1.6 & 65 & 3.4 & 64 & 5.8 & 70 \\
\hline 15.03 .95 & 5.7 & 113 & 4.1 & 98 & 72 & 2.2 & 91 & 4.1 & 77 & 6.5 & 78 \\
\hline 27.10 .95 & 5.8 & 114 & 4.0 & 97 & 69 & 2.4 & 100 & 4.3 & 81 & 7.0 & 84 \\
\hline
\end{tabular}

FVC: forced vital capacity; FEV1: forced expiratory volume in one second; FEF25, FEF50 and FEF75: forced expiratory flow at 25,50 and $75 \%$ FVC, respectively; $\%$ pred: percentage of predicted value. 


\section{Discussion}

We report a case of acute respiratory failure due to tracheobronchial involvement in CD. Specific lung localization in CD has previously been described but is rare $[1,10]$, whereas subclinical abnormalities, such as impairment of lung function parameters [11, 12], lymphocytosis in BAL [13] and increase of lung permeability [14] appear to be more frequent.

Bronchial and/or tracheal involvement in CD is uncommon and has rarely been discussed. To our knowledge, no case of respiratory failure associated with CD bronchial localization has been reported previously. In 1987, LEMANN et al. [8] reported two cases of simultaneous occurrence of segmental colitis and bronchial involvement, both revealed by dyspnoea and cough, with the same bronchoscopic findings of erythematous mucosa with small diffuse whitish granulations. In one case, biopsies revealed tuberculoid granulomas, both in bronchi and colon, whilst in the other case, bronchial biopsies showed erosion of the bronchial epithelium underlined by a polymorphic infiltrate and few epitheloid cells without granulomas. Colonic biopsies disclosed superficial ulcerations with tuberculoid granulomas. In 1991 IWANA et al. [9] reported one case of tracheobronchial localization in a 25 year old man, occurring $10 \mathrm{yrs}$ after a total colectomy for $\mathrm{CD}$. Bronchoscopy also revealed whitish granulations and biopsies showed squamous cell metaplasia of the bronchial epithelium and inflammatory cell infiltration, without granulomas.

In this case, sarcoidosis with colonic involvement was the main differential diagnosis but there was little evidence in favour of this diagnosis: there was no occular or cutaneous involvement, no mediastinal lymph node or lung involvement on HRCT, no alveolitis in BAL and the SACE level was normal. Moreover, intestinal sarcoidosis is exceptional, often asymptomatic, and always occurs in the context of otherwise obvious sarcoidosis [15-17].

The interest of this case also relies on the sequential bronchial histological findings, which were similar to those observed in CD bowel biopsies [18], indeed, initial bronchial biopsies revealed ulcerative bronchitis with microabscesses. Nonnecrotizing tuberculoid granulomas with giant cells were found in subsequent biopsies. These histological findings were observed, while the patient was not receiving any specific treatment. After 6 weeks of oral corticosteroid treatment, bronchial biopsies showed nonspecific fibrous changes without granulomas. These sequential histopathological findings are similar to those found in $\mathrm{CD}$, which typically include noncaseating granulomas and longitudinal ulcers during the acute inflammatory phase. In the remission phase, granulomas became rare and fibrous changes appear [18]. No granulomas were found in the colonic mucosa of our patient, but clinical evolution and histopathological findings were consistent with $\mathrm{CD}$, leading to the diagnosis of $\mathrm{CD}$.

Finally, our patient improved on oral and topical corticotherapy, as, has previously been reported in patients with inflammatory bowel disease and respiratory involvement. Meanwhile, pulmonary function tests showed a mild but persistent obstructive syndrome. This may be attributed to the patient's previous history of smoking, or due to irreversible damage caused by bronchial inflammation. Steroids have been shown to be highly effective in the majority of cases of airway inflammation in inflammatory bowel disease [1]. In those cases, inhaled steroids are beneficial in the long-term and a long-lasting response is often seen following such treatment. Since a definite progression from bronchitis to bronchiectasis has been documented in some cases that were not treated with steroids [1, 6], inhaled steroids should be used early as a first-line treatment, as they may prevent the occurrence of irreversible bronchial damage.

\section{References}

1. Camus PH, Piard F, Ashcroft TH, Gal AA, Colby TV. The lung in inflammatory bowel disease. Medicine (Baltimore) 1993; 72: 151-183.

2. Shah SM, Texter EC, White HJ. Inflammatory bowel disease associated with granulomatous lung disease: report of a case with endoscopic findings. Gastrointest Endosc 1976; 23: 98-99.

3. Henrion F, Bretagne MC, Neimann L, Flechon PE, Canton PH, Hoeffel JC. Association exceptionnelle de lésions pulmonaires, cutanées et d'une iléite terminale chez un enfant de 11 ans. J Radiol 1982; 63: 123-126.

4. Puntis JWL, Tarlow MJ, Raafat F, Booth I. Crohn's disease of the lung. Arch Dis Child 1990; 65: 1270-1271.

5. Dome JW, Kullnig P, Petrisch W. Colobronchial fistula: a rare complication of Crohn's colitis. Am Rev Respir Dis 1990; 142: 1225-1227.

6. Kraft SC. Unexplained bronchopulmonary disease with inflammatory bowel disease. Arch Intern Med 1976; 136: 454-459.

7. Yaffe BH, Korelitz BI. Sulfasalazine pneumonitis. Am J Gastroenterol 1983; 78: 493-494.

8. Lemann M, Messing B, D'Agay F, Modigliani R. Crohn's disease with respiratory involvement. Gut 1987; 28: 1669-1672.

9. Iwana T, Higuchi T, Imajo M, Akagawa S. Tracheobronchitis as a complication of Crohn's disease: a case report. Jap J Surgery 1991; 21: 454-457.

10. Rodgers BH, Clark LM, Kirsner YB. The epidemiologic and demographic characteristics of inflammatory bowel disease: an analysis of a computerized file of 1,400 patients. J Crohn Dis 1971; 24: 743-753.

11. Bonniere PH, Wallaert B, Cortot A, et al. Latent pulmonary involvement in Crohn's disease: biological, functional, bronchoalveolar lavage and scintigraphic studies. Gut 1986; 27: 919-925.

12. Heatley RV, Thomas P, Prokipchuk CJ, Gauldie J, Sienewicz DJ, Bienenstock J. Pulmonary fuction abnormalities in patients with inflammatory bowel disease. $Q$ J Med 1982; 203: 241-245.

13. Wallaert B, Colombel JF, Tonnel AB, et al. evidence of lymphocyte alveolitis in Crohn's disease. Chest 1985; 87: 363-367.

14. Wallaert B, Adenis A, Lecouffe P, Collet R Colombel JF, Machandise X. Increased pulmonary epithelial permeability in Crohn's disease. Am Rev Respir Dis 1990; 141: A319.

15. Gould SR, Handley AJ, Bernardo DE. Rectal and gastric involvement in a case of sarcoidosis. Gut 1973; 14: 971-973.

16. Boruchowicz A, Wallaert B, Vandermolen P, Colombel JF. Sarcoidose et tube digestif. Gastroenterol Clin Biol 1994; 18: 1119-1128.

17. Maccormick PA, O'Donoghue DP, Fitzgerald MX. Crohn's colitis and sarcoidosis. Postgrad Med J 1986; 62: 951-953.

18. Geller SA,. Pathology of inflammatory bowel disease. In: Targan SR, Shanahan F, eds. Inflammatory Bowel Disease. London, Williams and Wilins, 1994; pp. 341-344. 